\title{
Homenaje a la vida y obra del filósofo Édgar Garavito
}




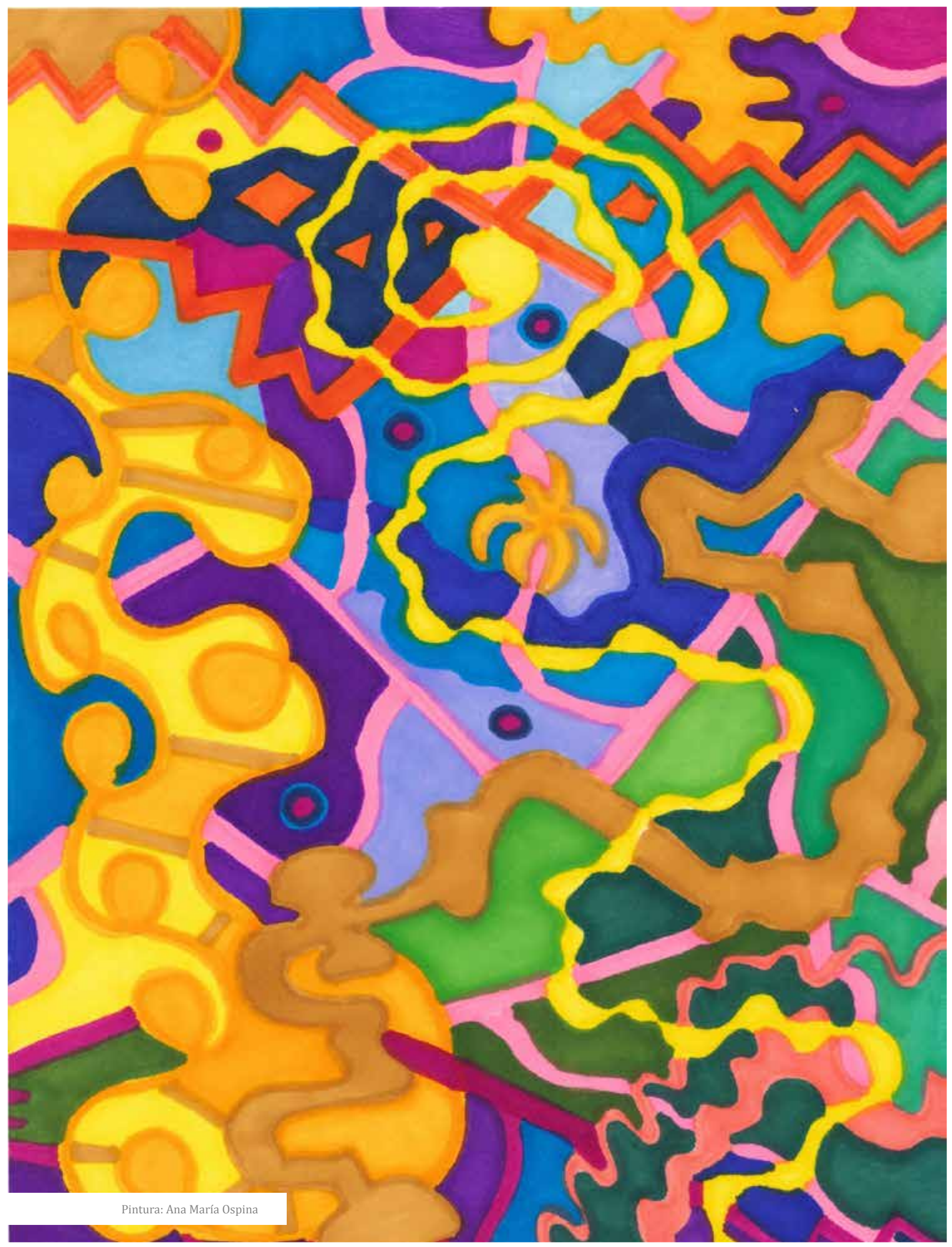




\section{Homenaje a la vida y obra del filósofo Édgar Garavito}

La labor investigativa, expositiva y creativa del filósofo Édgar Garavito en las décadas de 1980 y 1990 ha traído repercusiones enormes pero imperceptibles en nuestro medio universitario: sus cursos en la Universidad de los Andes, Universidad Nacional, Universidad Javeriana, en la Alianza Colombo Francesa y sus conferencias magistrales, siempre acogieron un público inmenso y entusiasta que se transformó en ellas y es hoy en día el propagador de ese pensamiento en universidades y diversos estamentos educativos e investigativos del país. Varios profesores de la Universidad Pedagógica Nacional, que vivimos esa experiencia filosófica con Édgar nos hemos reunido para proponer este proyecto con el fin de recuperar la obra inédita del filósofo publicándola en una co-edición con la Universidad Javeriana, presentar la obra ya publicada en un curso magistral que se desarrolló durante el primer semestre del 2014, y realizar una exposición y un conversatorio que presente la obra y el legado de este filósofo muerto hace 15 años.

La Revista Pedagogía y Saberes se une a este homenaje publicando los textos de los profesores y amigos que, por invitación de Consuelo Pabón, la gestora de estos eventos, quisieron acompañarla recordando lo que significó este pensamiento para ellos.

A continuación transcribimos las palabras de cada uno y agregamos algunos fragmentos inéditos del trabajo de Édgar, seleccionado por la colega Consuelo Pabón, en el que se percibe el lenguaje, el tono y la fuerza de los planteamientos que estamos empeñados en recuperar y difundir.

\section{El Editor}

Fecha de recepción: 3 de mayo de 2014 Fecha de aprobación: 6 de junio de 2014

Pedagogía y Saberes No. 40 Universidad Pedagógica Nacional Facultad de Educación. 2014, pp. 133-145 


\section{El pensamiento del afuera}

\author{
Clase de Édgar Garavito \\ Universidad Nacional, sede Medellín \\ 31 de mayo de $1996^{1}$
}

[...] El pienso de Descartes creaba una específica relación con el mundo, un encadenamiento con el mundo, con la existencia. Cuando Blanchot y Foucault rompen esa relación a partir de este principio: "Hablo, luego hablo" poniéndose en el afuera del "pienso luego existo", lo que están es rompiendo la relación entre ese pienso y esa existencia y el encadenamiento de las cosas del mundo a partir de esa existencia; con esto están promoviendo la entrada de un afuera; así permiten una respiración en filosofía, escapándose del encierro de este pensamiento del adentro, representativo. Para que el pensamiento del afuera entre, entonces, se trata de... algo muy importante, y es peligroso, se puede estar visitando el umbral donde alguien puede ser calificado de esquizofrénico, porque es como si alguien interrumpiera el lazo que tiene con el mundo; interrumpir el lazo con el mundo, interrumpir lo que ata nuestro pensamiento con el mundo. Y para darle toda la importancia a esa relación: son los procesos de los que hablaba alguien que estudió la esquizofrenia, pero era de formación filosófica, se llamaba Carl Jaspers, quien trabaja mucho sobre la esquizofrenia y él dice: la esquizofrenia no es el proceso mismo o no es los cortes que se hacen en la relación con el mundo. Ahí no hay ninguna esquizofrenia. Lo que es esquizofrénico es la relación que el sujeto mantiene con el proceso de conexión o desconexión entre las cosas del mundo. En el mundo en sí mismo no hay esquizofrenia; lo que es esquizofrénico es la relación subjetiva que se tiene con la desconexión, por ejemplo con pasar por un silencio... [En ese momento se escucha un sonido de avión y la voz del expositor se silencia obligatoriamente].

[Luego continúa] Por ejemplo, que alguien aprovecha el paso de un avión y entra en un profundo silencio, y no vuelve a decir nada, se queda en silencio; ese silencio en sí mismo no tiene nada de esquizofrénico, si el sujeto se angustia, si le es muy difícil guardar el silencio, ya ahí hay una relación patológica con el silencio, pero también el silencio podría ser algo deseable. 0 sea, darle toda la importancia a un corte

1 Este texto forma parte de una clase que Édgar Garavito dictó en la Universidad Nacional, sede Medellín, en 1996. Lo que alcanzamos a transcribir es solo la tercera parte del curso dictado ese día. El texto es una transcripción desde la oralidad, desde una grabación que un estudiante aportó. Se ha respetado la forma oral, más libre, más vital y con ella mostramos partes intensivas de material inédito (Consuelo Pabón). de la cadena, darle toda la importancia a un silencio, a una intermitencia, a lo que corta una decibilidad (lo que es dicho) o lo que corta la visibilidad. Por ahí se trabaja mucho en la literatura contemporánea, sería la literatura que realmente vale la pena hoy, una literatura en donde se le da toda la importancia al corte, a la ruptura de la cadena lógica del discurso... Si se toma un texto literario como el de Mallarmé, es moverse en un campo del lenguaje, en el que las palabras se llaman unas a otras por la resonancia que hay entre ellas; que un poema no signifique nada, ese era el problema de Mallarmé, y que sin embargo, al leerlo se sienta toda la intensidad del poema. Allí habría toda una construcción de lenguaje que mantiene a Mallarmé por fuera, tanto de algo del sujeto que se está expresando, como del objeto del cual está hablando y la significación de lo que está diciendo. Mallarmé es un poeta de la segunda mitad del siglo XIX, y ya intenta un lenguaje que rompa esas relaciones rígidas con el sujeto, el objeto y la significación.

¿Para qué reivindicar ese "hablo, luego digo que hablo", como relación con el afuera? Para reivindicar lo que sería una grieta, una apertura, una posibilidad en la que el sujeto que habla se fragmenta, porque no es realmente la expresión de una psicología del sujeto, no es un yo psicológico el que está hablando, no es una entidad, es una fragmentación del polo subjetivo que se dispersa, que desaparece, y también una fragmentación del polo objetivo, de lo que estamos hablando, del objeto, que también se dispersa, desaparece, se diluye; es una posibilidad de movernos con el lenguaje "hablo, luego digo que hablo", donde lo que importa no es ni el sujeto que habla, ni un sujeto que escucha, ni un objeto del que se habla, ni un lenguaje, ni un discurso lo que está siendo transmitido; no es un intento de comunicación, por ejemplo, ni tampoco hay una responsabilidad en lo que se está diciendo, nada de eso, sino que más bien, es la pura exterioridad del lenguaje, el lenguaje en su exterioridad. Llamaríamos adentro del lenguaje todas esas relaciones con un sujeto, con un objeto con un significado, con una expresión, con una manifestación, con una designación de un objeto, etc., esto sería el adentro del lenguaje; "hablo, luego digo que hablo" estamos en el puro afuera.

En la literatura, volvamos un momento ahí, cada vez más la literatura realmente innovadora, es la que se toma a sí misma como mundo lenguaje, se elabora a partir de ese propio mundo lenguaje. Ya no la literatura que nos está contando de una situación natural o social, que tiene como ese referente social; en ese sentido, para mí los últimos textos de García Márquez me parecen un gran paso atrás: ya tomar como objeto de la literatura un secuestro, es realmente no 
trabajar lo importante, que es el mundo lenguaje. Él ya lo había trabajado muy bien en libros como $E l$ otoño del patriarca. Lo que importa en ese libro no es tanto la referencia a la dictadura, lo que importa allí es el trabajo con la palabra misma, con el lenguaje, es un discurso poblado de discurso indirecto libre en el que no se sabe quién habla, quién es el dueño del discurso, si el que es el autor de la novela es el patriarca o si es García Márquez o si García Márquez es un personaje dentro su obra o qué. Es esa dimensión de indiscernibilidad la que enaltece esa obra. Pero en las últimas obras, no, realmente es un retroceso, por esto se convirtió en literatura de supermercado, se consiguen los libros en el supermercado. Es seguir creyendo que hacer literatura es tener como referente un objeto social, un conflicto social, un problema y hacer la literatura de la misma manera clásica, con los personajes, los diálogos, etc.

Cuando hablamos de literatura contemporánea hablamos de Mallarmé, de Joyce, incluso de Holderlin, un poeta que vivía en casa de un campesino a finales del siglo XVIII: los Poemas de la locura de Holderlin, poemas que se llaman invierno, verano, otoño, primavera porque fueron escritos en esa espaciotemporalidad... Es la creación de un espacio literario en donde uno se siente llevado a una plenificación, una ampliación del espacio, pero donde, mirando bien, no hay un objeto, no hay un referente, no hay una significación. En esa medida Holderlin estaría más próximo de ese "hablo, luego digo que hablo" que esa literatura básica de supermercado.

En el lenguaje del afuera es como si la palabra se desarrollara a partir de sí misma. Como si la palabra se desplegara a partir de sí misma, como si la palabra creara su propia espacialidad, sus propias invenciones, sus propios canales, la palabra no la crea el sujeto, sino que la palabra misma llama otras palabras y se articula con ellas... Un lenguaje que se implica a sí mismo y se entiende desde sí mismo. Y podemos relacionar este fenómeno de la literatura con el de las artes visuales: Un arte que ya no puede ser descifrado desde afuera en el sentido de la crítica, que tenga como un lenguaje universal que pueda decir esto vale la pena y esto no; sino más bien que la crítica no podría entenderse sino dentro del mismo lenguaje pictórico: una pintura que se implica a sí misma, una literatura que se implica a sí misma, una música que se implica a sí misma. Como si se pusiera el habla, la música, un sonido, una imagen dentro de una lengua que le pertenece a esa diversión de ese habla, de esa música, de esa imagen. Por esto cada vez más resulta vergonzosa la posición del crítico del arte, de la literatura. Es todavía seguir creyendo en el lenguaje universal, en principios universales desde donde cuestionamos las creaciones del arte y la literatura contemporáneos.

(Intervención: "Y además porque el crítico no hace una creación alterna que valga la pena, pero se limita a criticar, y si uno critica una cosa es porque es mejor, y generalmente no...")

El único crítico posible es quien está impregnado de la realización de la obra, está involucrado en ese modo de ser propio de la obra. Bien, ahora continuemos con lo que dice Foucault en relación con el pensamiento del afuera. Sería un lenguaje que ocupa, lo que llama Blanchot, un espacio neutro. Neutro no en el sentido de algo que no tiene una militancia, que no es una actividad creativa, guerrera, transformadora; en realidad la idea de lo neutro en nuestra cultura es de alguien demasiado pasivo que no sabe qué escoger; no neutro en ese sentido. Más bien un espacio neutro en relación con que no hay sujeto, no hay objeto, no hay un referente; es neutro en tanto que silencia al sujeto, silencia al objeto, implica el olvido de ese sujeto y ese objeto, pero no caer en la pasividad, sino que más bien es un neutro activo, que busca una creatividad, así sea desesperada, una vitalidad, un vitalismo, una fuerza, en donde para poder crear se rompen las formalizaciones rígidas de la creación clásica y moderna. En otras palabras, el nuevo lenguaje solo aparece en la medida en que desaparezca el sujeto que lo está controlando; es como llevar al sujeto a su desaparición para que podamos entrar en la construcción de lenguaje. Así mismo en relación con los objetos. ¿Qué es un pensamiento del afuera? Resumámoslo, un pensamiento por fuera de la relación del sujeto y el objeto, por fuera de toda subjetividad, por fuera de toda psicología, que dispersa la subjetividad y las certidumbres a las que estábamos acostumbrados del sujeto y el objeto, que dispersa la interioridad de la reflexión filosófica.

Ahora, para hacer una referencia a lo que estuvimos trabajando sobre la arqueología del saber, de alguna manera cuando Foucault hace esta propuesta como una nueva dirección para poder trabajar, investigar, pensar; esa arqueología de Foucault es elaborada a partir del pensamiento del afuera. Si entendemos como pensamiento del adentro lo que sería un pensamiento de la conciencia, del conocimiento, para finalmente llegar a la ciencia. Eso sería el vector propio del pensamiento del adentro, seguir pensando que el conocimiento es elaborado desde una conciencia y ese conocimiento después nos lleva a una ciencia o a un conocimiento reflexivo. Es, no partir de la conciencia y en eso Foucault y Blanchot son nietzscheanos. Nietzsche en la gaya ciencia se muestra contrario a todo intento de restituir la conciencia, de hablar desde la conciencia. El pensamiento del 
afuera sería el que ha destituido la conciencia como punto de partida. Nietzsche en la gaya ciencia dice lo siguiente: podríamos, pensar, sentir, querer, recordar, obrar, en todas las diferentes formas de la acción, sin necesidad de tener conciencia. Sería posible la vida entera sin necesidad de que la contemplásemos como en un espejo, como una reflexión y es muy cierto que la mayor parte de la vida se desliza en nosotros sin conciencia, sin reflejarse, aunque un filósofo a la antigua se escandalizaría de una proposición de esta naturaleza. “¿De qué sirve pues la conciencia?", termina diciendo Nietzsche, parágrafo 354 de la gaya ciencia, de qué sirve pues la conciencia si para lo esencial es superflua. Y Nietzsche se pregunta: “¿Por qué hay conciencia?". Y él responde, "hay conciencia porque nos interesa comunicarnos con el otro, por esa necesidad de comunicación; o en términos psicoanalíticos, por la relación con el otro". Frente a ese otro es que se constituye una relación de conciencia. Pero si se pasa por el silencio, por la no comunicación, entraríamos en una creación automática de pensamiento que no estaría referido al yo y al otro, más bien, le daríamos cabida a unas fuerzas primarias por fuera de esa relación consciente. Tengo otra cita de Nietzsche: "Mi opinión es que la conciencia no forma parte del ser del hombre, que la conciencia más bien corresponde en el hombre a lo que hay en él de rebaño, de tendencia a vivir en comunidad". La conciencia solo se ha desarrollado sutilmente en aquello que guarda relación de utilidad para la comunidad y el rebaño. Y advierte además, que todo implemento excesivo de la conciencia es un peligro. ¿Un peligro para qué? Para la creación. ¿No lo viven ustedes con la creación artística? Cuanto más reflexionan sobre lo que van a hacer, menos lo pueden hacer. El incremento excesivo de la conciencia es un peligro... Y añade Nietzsche criticando a la cultura europea de su época, y de esta época: "Todo el que vive entre los europeos puede observar que la conciencia en ellos es una enfermedad". ¿Por qué es una enfermedad? Es la enfermedad que hemos llamado aquí el pensamiento del adentro. Que es el pensamiento que se repliega sobre sí mismo, sobre su eje de conceptos y de imágenes, que queda allí satisfecho de su condición de adentro y no se atreve al acto creador. Por qué dice Nietzsche que las grandes revoluciones advienen intempestivas, como un acontecimiento inesperado y de ruptura. Quizá por eso, no se trata de un proceso de acumulaciones, sino un atreverse al corte, a la destitución, a la demolición para pensar la diferencia. Nietzsche siempre fue el más radical de todos. Cuando Deleuze escribe sobre la historia de la filosofía, sobre Spinoza, sobre Nietzsche, sobre Kant, Leibniz, etc, dice: "Yo siempre le colocaba una máquina deseante, filosófica; la colocaba en relación con el discurso de los filósofos y desde ahí manejaba el discurso". Cuando trató de hacer eso con Nietzsche, se dio cuenta de que Nietzsche le aplicó la máquina a él. Y es que Nietzsche fue el único al que no pudo aplicarle su manera de proceder. Y claro, Deleuze hace un gran libro sobre Nietzsche, que se llama Nietzsche y la Filosofía. Y siempre sintió a Nietzsche como su paralelo, como su maestro. Foucault tiene también la misma posición de Nietzsche en relación con la conciencia. No habla de conciencia sino de arqueología, y la arqueología se trataría no de un sujeto, sino que se trataría de unos enunciados, de una materialidad de cosas dichas que no reposan en una conciencia, que no residen en un yo consciente, sino que están ahí dichas en el espacio social, en el libro, en el enunciado colectivo, en el computador. Tienen una vida social campo social donde está dispuesto lo dicho, no la conciencia, sino lo dicho, el "hablo, luego digo que hablo"...

\section{Fragmentos inéditos}

\author{
Clases de Édgar Garavito \\ Universidad de los Andes \\ Antropología, $1981^{2}$
}

\section{La transcursividad y el cuerpo (clase 1, "Curso introductorio")}

Bueno, vamos a explicar hoy lo que haremos durante el año. El sentido de lo que haremos. Una vez más es necesario tomar distancia con respecto a la verdad $\mathrm{y}$ al saber puro. El saber verdadero no existe. No hay algo que por su naturaleza sea verdadero, ni que legitime la denuncia de los errores. No se trata, por ejemplo, de la verdad de los indígenas, ni del error de los antropólogos o viceversa. Se trata sí de entender que para un periodo histórico hay un producto que se llama saber verdadero, que se produce y funciona como verdad, ejerce la exclusión e invalida otros saberes. Como consecuencia tenemos que la verdad

2 Dentro de la investigación que estamos realizando sobre los manuscritos de los cursos de Édgar Garavito, hemos encontrado materiales muy importantes que serán publicados en el momento oportuno. Sin embargo, para esta revista en la que aparecen testimonios de varios de sus discípulos y de la manera como aplicaron las enseñanzas de Édgar en sus propias líneas de trabajo, nos parece pertinente publicar estos fragmentos de un curso introductorio en la Universidad de los Andes en 1981, donde de manera radical, Garavito propone una experiencia diferente de vivir un curso, a partir de un plano de consistencia nómada que agencia el pensamiento desde ciertas aventuras singulares, acontecimientos que nos transformen: haciendo madrigueras y no creando centros, eludiendo las capturas, trazando líneas de fuga, creando nuevas realidades (Consuelo Pabón). 
no se descubre, sino que se inventa. El saber no se relaciona con un objeto, con un cuerpo del que extrae una verdad que se observa y se encuesta. El saber se relaciona, sí, con unas técnicas de poder que producen enunciados, legitimados por derecho, no por hecho. Por ejemplo, en el proyecto sobre política indigenista que trata de introducir Turbay, el indígena es producido por patrones occidentales preestablecidos que le dicen un deber ser y que buscan una estrategia de su integración al deber ser. Se impone el patrón de desarrollo político social y económico, se impone el patrón de la propiedad, y se dice que eso es la dignidad humana. (A propósito de este proyecto de ley es necesario crear un grupo de investigación con sesiones extraordinarias que estudie el proyecto mismo y sus consecuencias).

Así mismo en el fondo, no se trata de la justicia, o de luchar por "mejorar la justicia", por una justicia más justa, contra las injusticias de la justicia. Eso es promover el sujetamiento a las técnicas de poder que producen algo como justo o verdadero. Se trata más bien de luchar contra la tecnología de poder, salirse y transformar y no luchar en el interior de ella. Más concretamente, no parto de la idea de estar en la verdad, en ese fondo de angustia en el que se debate el ser o no ser identificado con la verdad, la angustia como moneda para el cambio de ideas. En una clase tradicional, eso es lo que se presenta en la relación maestro/alumno, una especie de nupcias en las que mamá verdad y papá maestro tienen unos hijos y a través de ellos se promueve la verdad en relaciones de carencia y sujetamiento. Aquí, en cambio, no digo verdades todo el tiempo, tampoco digo que me equivoque. Más bien parto de un plano de consistencia caótico donde vivo completamente equivocado. Ese es el referente, plano de consistencia donde todo es posible: es necesario el caos para poder pensar sin sujetamientos, para poder producir acontecimientos que rompan con lo que acontece. Por esto la reivindicación del azar y lo probable versus Hegel, quien al decir que todo lo real es racional, excluye la mayor parte de las cosas de la vida, que son irracionales... Captar los acontecimientos como el esplendor que nos hace señas en lo que acontece, nos esperan, circulan, son captados en múltiples direcciones: una idea que brilla en una página, una escena inolvidable, un flash de claridad, una fotografía... Aquí tratamos es de crear un territorio, de conectar campos, espacios por medio de caminos, de desbloquear zonas, crear corredores de fuga, zonas de concentración; crear un espacio con canales, invertible, modificable, con múltiples entradas y salidas, con múltiples usos. Si un cazador de la verdad, que busca lo sistemático, la piel hermosa de la verdad y espera con su escopeta nuestra aparición en el hueco central, no saldremos por allí, sino que apareceremos simultáneamente en dos huecos diferentes. Esa es la relación del cazador y el conejo, o del gamín bogotano y la policía. Se trata de un mapa y no de una estructura de sujetamiento. Crear pluricanales y no un monocanal represor.

De manera que esto no es una clase. Aquí no dictamos una clase (profesor verdad). Aquí construimos una madriguera. Esto no es un curso sino una banda, esto no es una clase, esto es una madriguera.

\section{Cuerpo de consistencia del curso: nomos}

Alguien, al terminar el curso el lunes pasado me dijo: "Bueno, he oído varias cosas, algunas interesantes. Pero ¿cuál es el proyecto? ¿Hacia dónde vamos? Objetivos". Y era una pregunta casi angustiada, como si se preguntara cinematográficamente ¿dónde está el piloto? La pregunta me pareció importante pero curiosa, porque el proyecto me resulta evidente, así es que habrá que indicar cuál es el cuerpo de consistencia del curso, al cual remitimos los objetos parciales, para evitar la sensación de dispersión. Lo que se propone es lo siguiente:

1. Crear un espacio abierto trazando un panorama amplio y no un panóptico (evitando las ideosferas) compuesto por elementos parciales, extralimitados, determinados por fuerzas y no por formas, porque estamos convencidos de que para poder pensar es necesario forzar el material intelectual.

2. Tal espacio, pese a ser abierto y extralimitado, no es por eso público; es un espacio secreto de madriguera, con microcanales de transmisión del discurso, y así vivir el discurso en diferentes niveles y diferentes planos. La transmisión de pensamiento no se da por la vía del sujetamiento sino de la propagación. Evitando los conceptos gruesos, representativos, generalizantes, que es más lo que ocultan que lo que aclaran y que dependen de una voluntad de verdad. La propagación como forma micropolítica de transmisión.

3. Trabajar en lo posible con un elemento activo: el deseo. Captar y usar flujos de deseo. Deseo fluyente, línea de fuga. Se trata de ser capaces de atravesar los dispositivos de poder e ir hacia su extralimitación. No para reintroducirlos en la organización (reterritorialización) sino para dar consistencia desde el borde -un pensamiento nuevo de múltiples usos-. 
4. Para ello, uso de nociones inexactas, como manera rigurosa y exacta de decir algo. Con ellas, a) evitar el uso de conceptos ideosféricos, b) evitar los enfoques demasiado específicos, c) evitar el no trabajo, es decir donde cada cual habla de cualquier cosa sin tener una consistencia. Se propone un espacio abierto de interacciones, incluso conceptos no arborescentes, referidos no a esencias sino a circunstancias. Es posible gritar un concepto, crearlo, sin necesidad de estructurarlo en un sistema cerrado. Con los conceptos pasa como con las consignas políticas y los movimientos, por ejemplo, "todo el poder para los soviets" en 1917 implicaba Revolución; luego en Stalin y en 1981: promoción de una forma centralizada de poder totalitario. Hay nociones y conceptos cargados de fuerza crítica y libertaria, pero que al insertarse en un sistema cerrado, pierden su pathos. Así, proponemos como tarea filosófica crear conceptos y nociones pero no ideosféricos.

5. Molecularizar los casilleros teóricos (ideosferas) para favorecer un panorama amplio y eficaz, privilegiar líneas de trabajo, lo importante es la línea de trabajo, la mirada y no el sistema estructuralista, funcionalista, dialéctico, etc.

6. No preguntar qué significa lo que se dice aquí, no hay un significado oculto por comprender. Preguntar, sí, cómo funcionan y se conectan los objetos parciales con un espacio abierto, como se conectan con la vida.

7. Se trataría en el límite de crear una mirada teórica y política, una reactualización de la izquierda, una actitud revolucionaria de innovación que evite la estructuración y los sistemas cerrados. El terreno del adversario es un sistema cerrado. Hay que hacer algo pero jamás en el terreno y con los instrumentos del adversario. Esta es entonces una invitación a crear en un espacio abierto.

\section{Édgar Garavito, filósofo del transcurso}

\section{Consuelo Pabón ${ }^{3}$}

Mi exposición tendrá dos niveles de aproximación. Un primer nivel es el de la vida amorosa y creativa que tuvimos durante 17 años; un segundo nivel, es el de su filosofía del transcurso que hoy introduciré

\footnotetext{
3 Filósofa, Universidad de París VIII.
}

brevemente y que pretendo profundizar a lo largo de las conferencias que vengo realizando durante este primer semestre de 2014 en el Auditorio Paulo Freire de la Universidad Pedagógica. Se trata de niveles que se entrecruzan en eso que hoy llamamos una vida filosófica. El texto se desdobla entonces de varias maneras de expresar esa vivencia.

Hablemos de vivir en el afuera, en una condición límite en donde el compromiso conyugal era más con la filosofía que con nosotros mismos. Éramos incluso negligentes con nosotros mismos, en el sentido de Blanchot. Vivíamos en la sobriedad suprema de un cuarto con colchoneta, una mesa de escritura que se transformaba en tabla para comer, unos pocos libros y una poca ropa... y muchos cuadernos escritos, anotaciones de clases, esa era la biblioteca.

En la extrema sobriedad y minimalismo, en esa extraña aristocracia del que posee solo lo esencial y no carece de nada, así vivimos, así fluimos rizomáticamente, siempre con el equipaje tan ligero que nos permitiera salir en cualquier momento y crear en $\mathrm{el}$ exilio otros modos de vida... Sea en la urbe parisina o en las selvas del Carmen de Apicalá, o en Medellín, vivíamos de trasteo en trasteo, con gatos y luego con Casandra, como gitanos fluimos durante 17 años.

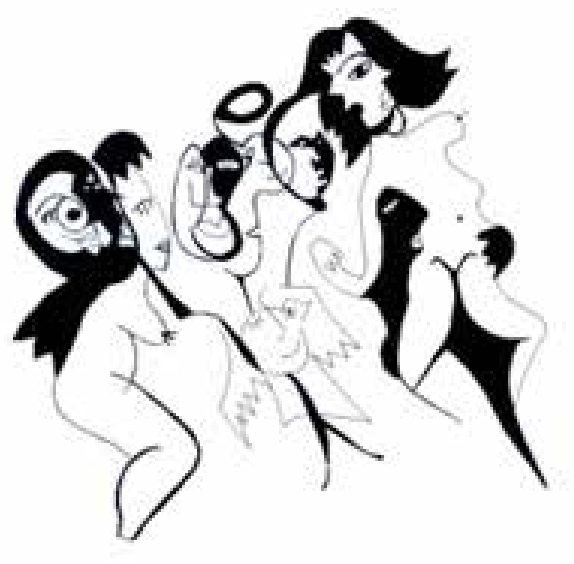

Figura 1. Dibujo de Consuelo Pabón

Y digo rizomáticamente porque el juego consistía en que no éramos dos, no éramos pareja binaria, sino una multiplicidad que pululaba destituyendo las identidades fijas y muchas veces, demoliendo todas las certezas. De ahí que ese era el plano de inmanencia de la relación y de la producción filosófica. La propuesta de Édgar fue clara: alianza para construir una vida filosófica y no identidad matrimonial. Ruptura de la doxa con respecto a lo que implica una relación amorosa: vivir construyendo paradojas eróticas, políticas, artísticas, para no caer en las redes de la identidad. 


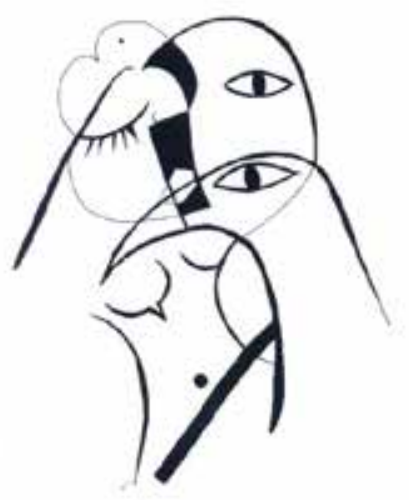

Figura 2. Dibujo de Consuelo Pabón

En esta semblanza tengo entonces que decir que más importante que la historia personal, más importante que hablar del individuo Édgar, de la identidad Édgar, tengo que hablar de una pluralidad de voces que hicieron posible su creación filosófica: de Édgar Garavito a los heterónimos encarnados por Lev Otgar hay toda una vida filosófica que se traduce en un concepto: el transcurso. Por esto, más que una semblanza de Édgar Garavito haré una presentación intensiva de lo que fue su pensamiento.

En el epitafio de su tumba encontramos la frese: "Supo desprenderse de sí y del otro". Añadiremos que supo transgredir. Que su pasión fue hacer entrar la vida en el lenguaje, rompiendo las formas identitarias y fascistas de la lengua para dejar hablar el afuera, el tercero excluido, el transcurso o la multiplicidad de voces que hablan en nosotros mismos, más allá del sujeto psicológico.

Dedicó su vida a hacer filosofía, a la pasión de crear líneas de pensamiento que sirvieran de herramientas para enfrentar la sociedad de control que en ese momento estaba empezando a manifestarse: la sociedad de control fundada en las identidades, va a ser transgredida desde el concepto de transcurso, que estudia cómo se rompe la identidad y se pluralizan las voces de quien habla.

\section{Como dice en Escritos Escogidos:}

Mi problema es cómo incluir la vida en el lenguaje, cómo evitar que el lenguaje sea un instrumento que nos aleje de la vida y cómo en el fondo hacer que la vida y el lenguaje coincidan, para eso entonces, intentar una autonomía del lenguaje con relación a las formas de la lengua y una heteronomía de las voces que hablan con relación a la idea moderna de un autor único. (Garavito, 1999, pp. 15-16).

El concepto de transcursividad es el resultado de un sinnúmero de aventuras entre el caos, el orden y el cosmos. Es el grito de una vida que pasó por muchas muertes siempre buscando transgredir las leyes del castillo kafkiano que imponían una identidad demasiado severa:

La terapéutica filosófica aparece cuando se traza una línea de fuga entre el yo y el otro, o entre el sujeto y el objeto [...] lo que se intenta es que en el cruce de las dos dimensiones, aquel que escribe pierda el rostro [...] la transcursividad será la escogencia permanente de una función transformativa. (Garavito, 1999, pp. 141-142).

¿Cómo pensar aquello que es incesante transformación y que no está situado espacialmente?

Tal vez la transcursividad es una máscara del tiempo que atraviesa el lenguaje. El prefijo trans- está íntimamente ligado al tiempo: la transgresión, la transcursividad, la transformación son fenómenos esencialmente temporales, y no se trata ni del tiempo sagrado de lo eterno, ni del tiempo lineal del individuo. Acá, el tiempo se pregunta por sí mismo, por su tarea de destruir y transformar. Se trata del instante, se trata de un tiempo fuerza, de un tiempo intempestivo que al irrumpir, destruye las identidades, las leyes, las formas. Se llama Internet el tiempo desmesurado que rompe toda medida cronológica. Internet como instante límite del tiempo propio del transcurso. (Garavito, 1997, p. 27).

Terminemos esta semblanza con una imagen que nos da el mismo Édgar:

Cada mañana, procede del caos. El niño que despierta, despierta como diversidad. No sabe quién es, dónde está, es decir, se enfrenta al caos de su propia diversidad. Está alterado y solo adquiere seguridad al reencontrar y volver a nombrar los objetos que pueblan su entorno. Los objetos familiares hacen su aparición cotidiana y las relaciones entre los objetos crean la espacialidad donde se constituye la primera imagen de lo mismo. El espacio empieza pues a llenar el caos de la diversidad y ella es poblada por ritmos, movimientos, que permiten una armonía espacio-temporal desde donde se constituye la imagen de lo Otro y de lo Mismo. La existencia indeterminada no pasa a ser determinada sino gracias a un tiempo y a un espacio; ellos son quienes permiten una relación entre una identidad y un cuerpo y en su armonía, permiten la aparición de un yo psicológico. El otro es constituido gracias a una armonía espacio-temporal que crea una zona de intercambio con lo mismo [...] La imagen del otro y la imagen de sí se relacionan gracias a una espaciotemporalidad que las constituye. El otro guarda con lo mismo una relación vectorial de exterior-interior o si se prefiere de extimidad-intimidad. Pero el Otro no es el Afuera. Nuestra hipótesis a nivel estético 
es que el Afuera irrumpe a partir de una desarmonía espacio-temporal que deconstruye la relación del Otro con lo Mismo. Si se quiebra la armonía, irrumpe entonces lo sublime y la metamorfosis se hace posible: el durmiente se despierta. El armario, el escritorio, la chimenea, la ventana, las puertas han perdido el nomadismo del entresueño y ahora son rígidas, inmóviles, pesadas. También el yo se redefine dentro de su pesadez. Es posible que en ese momento angustioso el durmiente-despierto descubra la aterradora realidad de la captura. Pero la geometría de la alcoba, la rigidez de los muebles, la quietud inamovible de las mantas no son nada comparadas con la pesadez metálica de un humor viscoso que se ha apoderado de su cuerpo y que le impide el menor desplazamiento. ¿Inercia imaginaria? ¿Poder del significante? ¿Un padre demasiado severo? Todo eso es posible solo si se conserva el yo. Pero lo que se exige en este momento crítico no sería comenzar la práctica de un psicoanálisis, quizá interminable. Lo que se exige concretamente para que se levante el transgresor es un transcurso monologal acompañado talvez por una transformación estética. Entonces, en el durmiente-despierto, salido de un cuento de Kafka, se produce una transformación que exige una máxima precisión. Acostado sobre la espalda dura como una coraza, el durmiente-despierto se percibe transformado en coleóptero. Una ruta de transgresión abandona la pesadez. Quizá se hace posible a partir de una herida, de una grieta que actúa a la manera de disyunción. Esa ruta es silenciosa y secreta. En el transcurso se necesitan grandes dosis de silencio y secreto puesto que está referido a un vacío originario con el que se hace posible desmontar el orden impuesto a las cosas y al Yo. La explicación de ese vacío está en que como fenómeno de transformación el transcurso es un fenómeno del tiempo. (Garavito, 1997, p. 190-191)

\section{Édgar Garavito: una vida filosófica}

\section{Carlos Ernesto Noguera ${ }^{4}$}

Édgar, querido Édgar: esta tarde nos hemos reunido aquí para arrebatarte del olvido. Nos hemos dispuesto para memorarte, para celebrarte. Hemos llegado hasta esta sala con un entusiasmo similar al que nos invadía cuando acudíamos, los jueves al final de la tarde, a la Alianza Francesa para escucharte. Hoy hemos decidido evocarte, convocarte. Hemos decidido traerte un poco, desde el oscuro olvido, a nuestras

4 Profesor Universidad Pedagógica Nacional. vidas actuales. A fin de cuentas nunca te fuiste del todo; la parca devoró tus huesos y tus carnes, pero ella no sabe del pensamiento, no sabe de la palabra, por eso estás aquí aún, en parte, con nosotros.

Querido Édgar, pocas veces conversamos. La verdad, sentía que no teníamos mucho que conversar; para conversar estaban los demás, con cualquiera se puede conversar, pero no a cualquiera se le puede escuchar, escuchar atentamente, escuchar de verdad, seriamente, felizmente, apasionadamente. Sin embargo, conversamos mucho contigo, cuando acababa cada sesión de los jueves y tú tomabas tu camino y nosotros nos íbamos al bar del lado para, ahí sí, poder hablar, poder decir algo y conversar contigo en tu ausencia. Quizás como hoy, tal vez esa fue la única manera de poder conversar contigo. Porque a ti había que escucharte, y a pesar de tus esfuerzos por hacer participativo ese encuentro semanal, por fortuna, casi siempre, eras tú quien hablaba, eras tú quien, finalmente, tenía algo que decir: algo que decir, verdaderamente, por eso tus cursos no eran clases: no pretendías enseñar nada, no pretendías mostrar nada. Querías algo más, buscabas, en esos jueves, en esas horas, en esa sala, quizá una invocación... ¿invocar qué? Quizá lo sublime, el pensamiento del afuera.

En todo caso, tus cursos no eran para reproducir lo que había dicho ya Foucault o Deleuze o Lyotard. Tus cursos no eran un espacio para la presentación o la representación de lo ya dicho, de lo ya sabido; tus cursos eran como un escenario para el pensamiento, para producir pensamiento. Y te preparabas para ello. Como un chamán o un monje oriental, ayunabas varios días antes: leías, releías, escribías, repasabas y ese día te colocabas tu traje negro, tu camisa blanca y tu sombrero y ante nuestra expectativa, con nuestra expectativa, oficiabas el ritual a la palabra/pensamiento. No se trataba de decir, no era cualquier palabra la que se debía pronunciar: sabías muy bien de la potencia del decir, habías escuchado a Foucault hablando de la parresia, entonces tratabas con cuidado las palabras, tomabas precauciones y te disponías ese día, en esas horas, ante ese auditorio, romper el adentro para evocar el afuera.

Ese era tu gesto: un gesto pedagógico que más allá de la enseñanza y del conocimiento, apuntaba hacia el pensamiento. Y como tú decías, todo gesto implica una categoría, entendida como una manera de proceder en el discurso, y una actitud, o sea, una manera de estar en el mundo. Tu gesto pedagógico era, entonces, el transcurso y la ejercitación. Tus cursos podrían confundirse con un monólogo; tal vez quisiste en ellos, a veces, hacer un diálogo, pero finalmente eran un transcurso en donde múltiples voces y personajes entraban en escena: Foucault, Deleuze, el Quijote, Turner, Blanchot, Velásquez, Artaud, Miguel Ángel y tanto otros. Ese era tu modo de proceder en 
el discurso, que al final era contra el discurso. Y ello con una actitud permanente, con una forma de estar en el mundo: la ejercitación constante, persistente; el empeño cotidiano contra la domesticación impuesta a través de la identidad, del yo. Ejercitación como lucha contra el yo, siguiendo las reglas de Blanchot: 1) "renunciar a todo intercambio con el otro, no ser incitado ni seducido por el otro exterior, sino más bien ser atraído por fuera de la relación yo-otro"; y 2) "ser negligente consigo mismo, no concederse importancia, pasar por el olvido".

Por eso Édgar, hemos titulado este memorándum "Édgar Garavito: una vida filosófica". Aunque pasaste en tu vida por el lugar de profesor de Filosofía, no fuiste un profesor; aunque escribiste varios textos de filosofía y tuviste título de Filosofía, no fuiste por ello un filósofo. Con tu gesto pedagógico/filosófico deviniste un filósofo, pero al modo antiguo, es decir, como alguien que vive filosóficamente, como un practicante de la filosofía, como un ejercitante, como un atleta espiritual. Viviste una vida filosófica, una vida de ejercicios, una lucha contra la domesticación que impone el saber/poder; por tal motivo no fuiste un académico, un intelectual reconocido como otros tantos de tu generación y anteriores que te sobrevivieron. Por tal motivo, sólo al final de tu vida ocupaste, un poco incómodamente, la condición de profesor. Por eso Édgar, querido Édgar, antes que tus libros, antes que tus escritos, lo que nos dejas es tu vida filosófica, tu ejemplo de atleta, tu lucha permanente por ser negligente consigo mismo, por abandonar todo discurso, todo diálogo, todo monólogo y alcanzar o evocar un transcurso. Vida de riesgo, pues como dijiste, todo transcurso, en el fondo, implica una muerte.

Quiero terminar este brevísimo memorándum con tus propias palabras:

El intento más bien ha sido el de mantener una escisión fundamental reconociendo que solo puede aproximarse a ese abismo que atrae y a la vez atormenta aquel que abandone el andar estrictamente discursivo y sea capaz, en el límite, de abandonar el ser en las puertas del abismo.

\section{En homenaje a Édgar Garavito}

\section{María Teresa Salcedo}

Como alumna del profesor Édgar Garavito en sus cátedras de Antropología Filosófica en la Universidad de los Andes durante la década del ochenta, comprendí la importancia de asimilar el gesto filosófico

5 Antropóloga urbana. en cualquier reflexión que tuviera que realizarse en las Ciencias Sociales y en la Antropología más específicamente. Para esos primeros años de la carrera de Antropología entendí que era más importante asumir un transcurso filosófico que anclarse antes a cualquier herramienta o metodología de recolección de datos. Creo que como maestro, esa fue una de sus enseñanzas más oportunas. Junto a esta forma de pensar filosófica era importante para Édgar asumir una conexión permanente entre el pensamiento filosófico y la vida cotidiana de cada cual: se trataba además de poder entender a la academia desde unos principios en los que la vida diaria de quienes se estaban formando como antropólogos, se conectara con la vida cotidiana de quienes fueran a ser investigados, del mundo mismo, de la naturaleza, de los otros. En otras palabras, la pedagogía de Édgar era la de pensar las trayectorias de la alteridad en las Ciencias Sociales desde prácticas no estrictamente académicas, que bajo su informado conocimiento se trataba de buscar recursos en las artes y en otras corrientes de pensamiento. Al mismo tiempo la enseñanza de la filosofía de Édgar consistía en crear herramientas críticas de la academia, desde las lógicas del sentido, las lógicas del juego, los trayectos nómadas de las relaciones entre los cuerpos, la naturaleza, los rituales y la tecnología. Y de forma importante, desde los microcosmos sociales.

Por lo tanto las clases de Édgar eran muy estimulantes porque su idea era la de crear unos espacios pedagógicos no-académicos pero sumamente informados por una estética filosófica que conectara con lo real y lo imaginario de la vida humana que requiriera de aprehensión. Aunque era claro que lo que se aprehende debe soltarse pues también requiere de un transcurso, de una transformación propia. Esto tenía mucho que ver con lo que Édgar pensaba de la identidad como concepto, y de las identidades de las personas. $Y$ en tanto la identidad es un concepto tan importante para la antropología, lo que se derivaba de allí para los antropólogos en formación, como era el caso de muchos de sus alumnos, era la urgencia y el disfrute de manifestar a la identidad de otros modos más complejos con respecto a los modelos que nos ofrecía el positivismo o el estructuralismo.

En efecto y objetivamente la identidad es más compleja que la de los modelos de la estadística o de la demografía, es decir, la identidad de las poblaciones que se quiere captar en las encuestas, y el trabajo de campo como herramienta cualitativa de investigación requería de una interacción con la imaginación, el juego, la magia, el placer, la curación y las prácticas cotidianas, porque de lo contrario la comprensión de los otros es incompleta. Pero la comprensión de los 
otros en sus distintas metamorfosis animales, vegetales, minerales y tecnológicas nos llevaría a entender para dónde iban las Ciencias Sociales, y en lo personal este es uno de los aportes de Édgar a mi formación.

Importante no dejar pasar que Édgar no era comprendido por sus colegas filósofos y sociólogos de esas décadas, quienes pensaban que su pedagogía y sus contenidos eran erróneos y contraproducentes. Al contrario, no solo las lecturas y las tendencias señaladas por él eran las más informadas, y muchos de los filósofos, escritores y artistas abordados en sus clases como Deleuze, Guattari, Foucault, Bataille, Attali, Blanchot, Turner, Kandinsky, Herzog y los surrealistas, son lecturas claves en los actuales programas de posgrado en todo el mundo, sino que la ausencia de información sobre estos autores en las universidades colombianas, tiene mucho que ver con la calidad de los contenidos superficiales que se imparten.

Pienso en la juventud de Garavito por el espíritu innovador con el que instalaba cada clase. Una instalación flexible, con mucha movilidad, con aportes de estudiantes que venían de diversos campos, lo que se transformaba en una nueva forma de enseñar que producía sus propios escepticismos entre académicos muy moralistas y enclaustrados en demasiadas convenciones.

Con ese espíritu de la transgresión como equipaje simbólico, de la crítica como transgresión, y de la transgresión como propuesta artística en conexión con las ciencias sociales, es que he propuesto varios de los trabajos en investigación en Antropología urbana que pueden ser considerados un aporte desde las enseñanzas que Édgar Garavito nos transmitió a muchos. En todos estos sentidos Édgar está presente en mi práctica antropológica.

\section{Homenaje a Édgar Garavito}

\section{Alejandro Álvarez Gallego ${ }^{6}$}

No fui amigo personal de Édgar ni estuve cerca de él por mucho tiempo. Asistí a sus cursos en la Alianza Francesa, a un curso en la Universidad Pedagógica Nacional y otro en la Universidad Nacional, durante dos años consecutivos. Pude así profundizar en la obra de Foucault, Deleuze y Lyotard. Luego lo invitamos a hacer algunas charlas puntuales con maestros. Recuerdo especialmente una que hicimos en Villa de Leyva con maestros del occidente de Boyacá, en una iglesia colonial, que resultó ser un evento muy recordado por todos los asistentes, por la belleza

6 Profesor Universidad Pedagógica Nacional. del sitio, pero especialmente por la inspiración de la charla. Nos habló sobre lo sublime y el nomadismo. También asistí a algunas de sus charlas en Medellín.

Édgar Garavito fue para mí una experiencia fugaz; fugaz en el sentido de incandescente, de veloz, de intensa. El contacto académico que tuve con él fue para mí más formativo que mi maestría y mi doctorado juntos. Y eso es lo que me interesa compartir hoy en este homenaje, a 15 años de su adiós. Fue más formativa en primer lugar porque fue en realidad una experiencia vital. Édgar solía decir que lo que no le gustaba de las universidades era que se excluía de ellas la vida, la vida como experiencia; por los formatos, los horarios, la repetición de programas, el vaciamiento de los rituales. La experiencia de los cursos con Édgar fue realmente formativa, en mi caso, por tres razones:

Por la solemnidad con la que exponía sus ideas. No importa si era en un salón desvencijado como los de la Nacional o la Pedagógica, lo cierto es que sus conferencias eran casi un ritual religioso. Su compromiso con la palabra era evidente. Se dirigía a los asistentes de tal manera que producía un acontecimiento, es decir algo singular e irrepetible. Había allí un gesto, un modo de hablar y de decir casi teatral, profundo, pausado, metódico. Era inevitable escuchar, en todo el sentido de la palabra; escuchar hasta el silencio, escuchar sus pausas, sus ademanes, su puntuación. A nadie se le ocurría interrumpirlo para opinar o para preguntar. En sus palabras estaba su vida, a veces parecía meditando, descubriendo algo trascendental en el momento en el que hablaba, como si conversara con él mismo. Su figura era única, entre melancólica y alegre, irónica y escéptica; lucía poco arrogante, era completamente accesible, tímido, incluso, así lo percibía yo, pero al mismo tiempo distante. Todo su cuerpo hablaba. No tenía que decirlo, pero era evidente que en cada charla se jugaba la vida. No estaba repitiendo a nadie, estaba hablando de sí mismo, de sus búsquedas, de sus denuncias, de sus posturas éticas y filosóficas, de su percepción del mundo. Se exponía vitalmente. Tomaba tan en serio cada charla que era evidente que la había repasado previamente, la había meditado; por su compromiso con la palabra, claro, y con la filosofía, pero también por el respeto que tenía a sus oyentes.

En segundo lugar, porque no tenía pretensiones. No se proponía cambiar a nadie, no tenía objetivos, ni hipótesis, ni estrategia didáctica. Su discurso era su única y simple estrategia. La simpleza del dispositivo pedagógico hacía que en él apareciera la nuda vida, como diría otro filósofo. En la palabra desnuda estaba la magia de su seducción. Sí seducía, claro, creo que era fundamentalmente un seductor. Pero un seductor 
que libera, pues no creaba compromisos. Cuando salíamos de sus charlas yo sentía menos peso sobre mis hombros y creía que ya no tenía que engañar a nadie ni impostar más nada. Tenía menos culpas y menos responsabilidades, o mejor, tenía responsabilidades con mis búsquedas, más nada. Para esos años, a mediados de los años noventa, el fervor y el compromiso con los cambios sociales y políticos nos tenía cautivados a muchos, tal vez por el entusiasmo que había despertado en un primer momento la Constitución de 1991; pero al mismo tiempo vivíamos la crudeza de la guerra del narcotráfico y el uso macabro de la fuerza por parte del aparato del Estado que se puso a su servicio. Eran tiempos convulsionados y creo que se estaba produciendo allí una ruptura histórica que todavía no sabemos a dónde nos conducirá. Pero justo en esos tiempos Édgar nos proponía un extraño giro que suponía una tercera postura. Sin dejar de mirar de frente el drama que acontecía, sin dejar de tomar posición (nunca dejó de ser muy duro con esas modalidades de la guerra), planteaba la posibilidad de centrar nuestra mirada en aquello que se distanciaba de la binariedad causada por el conflicto; una mirada a aquello que no estaba capturado en medio de esa confrontación, a reconocer las líneas de fuga, el tercer excluido, en palabras que le gustaba retomar de Deleuze o de Michel Serres. Huir, en este caso no era dar la espalda, sino evitar ser capturado e inmovilizado por la trampa que la confrontación produce.

Tercero, porque sus tesis fueron completamente nuevas, intempestivas, movilizadoras. Sus lecciones eran provocadoras: Para mí fueron fundamentalmente tres. Primero, no vale la pena entregar la vida por nada, ni por nadie. No hay verdad que lo amerite, entre otras cosas porque no hay verdad. La verdad es un efecto. Segundo, hay que reír. Este gesto filosófico lo leí como la capacidad de entender que nadie la verdad es una ficción que se puede develar, y que detrás de las solemnes pretensiones de quienes profesan credos no hay más que la incapacidad de inventar caminos propios. La seriedad es una forma de ocultar esa incapacidad, y eso produce risa. Y tercero, el nomadismo. Hay que moverse, hay que desplazarse, justo cuando sentimos que las cosas marchan bien, cuando estamos satisfechos. Movilizarse para no estancarse, para no complacerse con lo que se tiene. El nomadismo es uno de los más difíciles modos de vida; en mi caso me cuesta mucho seguir. Muy pocos seres humanos lo logran, como creo, Édgar lo hizo.

Aprendí, en fin, qué significa ser maestro; y nunca habló de pedagogía, pues no era un tema de su preocupación. Pero supe con él que un maestro es quien dice verdad, quién habla de sí mismo sin pretender cambiar a nadie, pues es respetuoso de la experiencia del otro. Comparte su mirada, con honestidad profunda, pero no juzga al otro. Sigue su camino y revela sus dudas, no pretende saberlo todo, solo habla de sí, en su múltiples búsquedas. Édgar tuvo muchos alumnos, estoy seguro, pero a ninguno lo incluyó en una lista para calificarlo. Los que nos consideramos sus alumnos decidimos serlo, por nuestra propia voluntad. Entonces el maestro sería el que es seguido, no el que quiere que lo sigan. El momento de máxima intensidad entre un maestro y su alumno es aquel en el que el maestro le pide a su alumno que siga su propio camino. Tal vez su adiós fue la mejor forma de decirnos eso: "Sigan su propio camino". Y aquí nos tiene, aún, a varios de sus seguidores, haciendo ese esfuerzo interminable.

Muchos amigos, colegas y seguidores de Édgar coinciden en plantear que lo singular y lo potente de su mirada fue lo que hizo de su vida una vida filosófica, como le gustaba también imaginar su vida a Foucault. Pero creo que también podemos decir lo contrario, en mi caso puedo decir que lo que en últimas aprendí de él es que se puede hacer de la filosofía una experiencia vital, esto sería: crear-nos de otro modo.

\section{In memoriam}

\section{Adolfo Chaparro Amaya ${ }^{7}$}

Édgar Garavito era un filósofo y un hacedor de filósofos. Quizás mucho de su trabajo más original haya quedado trunco por la muerte prematura que lo interpeló, pero la cantidad de estudiantes y colegas encantados por la fuerza y el rigor de su discurso ha dado los más diversos frutos. Extraña manera de volver a cierto socratismo inflamado de pasión y escepticismo, de complejidad constructiva y pasión experimental. Mi tarea esta noche es recordar dos o tres líneas de fuerza de esa pasión. Las voy llamar, en su orden: cómo deshacerse del mundo, la producción de sí mismo y la carcajada transductiva.

Aunque suene un poco dramático, antes de vivir la muerte real, Édgar fue fraguando un estilo de vida que significaba un experimento constante con la muerte como búsqueda de las líneas de intensidad del pensamiento. Entre sus muchas estratagemas para explorar esa separación entre sujeto y mundo está la sobriedad como estilo personal, la sustracción de los objetos que pueblan el mundo a la mano, la intolerancia a los discursos redundantes provenientes de la publicidad o de la academia, la alergia incurable

\footnotetext{
7 Profesor Universidad del Rosario.
} 
a los protocolos burocráticos y a la retórica de la discusión políticamente correcta. Desde luego, lo interesante es cómo esa forma de estilizar el rechazo del mundo se fue volviendo un problema filosófico. Hay varios caminos, algunos más cercanos a la epojé fenomenológica o al escepticismo radical frente a los recursos de la filosofía para trascendentalizar los problemas, pero el que más recuerdo por la cercanía con su estilo de vida tiene que ver con el plano de inmanencia que propone el desierto y con esa suerte de personaje conceptual que encarna el anacoreta. Visto así, como un procedimiento metódico y vital, la cuestión era hasta dónde, prescindiendo de todo eso que llamamos el mundo del afuera, esto es, de todas las relaciones, las conversaciones, las transacciones cotidianas, aún en ese punto todavía, no podíamos evitar entender el adentro como una extensión del afuera, y viceversa. Instalados en ese desierto es prácticamente inevitable estar en conexión total con el afuera, pero en una instancia que no es la del referente que legitima nuestras proposiciones, sino como un espacio indiscernible de signos, segmentariedades, intensidades y líneas de fuga. Lo que hace pensar que el sujeto que se expone al afuera no es un yo que sufre o se adapta al mundo, sino una suerte de interioridad preindividual en constantes procesos de individuación. De ahí la dificultad para seguir nombrando "yo" a eso que normalmente se afirma como tal en el escenario social intersubjetivo, o mejor, de ahí el interés en precisar las capas de lenguaje, las afecciones impersonales, las inscripciones colectivas que adjudicamos a la identidad como su causa, cuando finalmente la identidad es un efecto de todo ello.

No es extraño que, para esa investigación, Édgar tomara como ejemplo la multiplicidad de voces y personajes que agencian la poesía y la persona misma del poeta Fernando Pessoa, cuyo apellido, en el límite de la ironía, significa justamente "persona" en portugués. La idea insistente de Édgar en sus cursos era justamente esa, según la cual, lo que habla en nosotros es una multiplicidad de conexiones, de líneas deseantes, de voces y simulacros, la cual, de alguna manera es ya una exploración de un afuera que, a su vez, debe ser entendido como lo más profundo de nuestra propia intimidad. Esa es la fuente de una experimentación de lo que, siguiendo a Foucault, podríamos llamar la producción del sí mismo, en lugar de la insistencia en interpretar el fondo auténtico de la identidad. Por eso, además de la crítica a la identidad psicológica, lo que le interesaba a Édgar era explorar hasta donde, más allá del discurso autoconsciente, hay una experiencia que nos rebasa y de la que tenemos que dar cuenta actualizando nuestra potencia de devenir. Así, frente a la representación de la identidad aparece una experiencia del devenir como acontecimiento que no se puede reducir a la reflexión de sí y sobre sí, de manera que siempre hay un resto, como diría Derrida, de lo no dicho.

Por último, algo sobre el concepto. Resultaba un poco extraño abrir la mirada sobe el acontecimiento como algo translingüístico $\mathrm{y}$, sin embargo seguir postulando, con Deleuze, el concepto como el objeto propio de la filosofía. Recuerdo que los ecos de esa paradoja alimentaron muchas intervenciones y preguntas sin respuesta aparente. Lo cierto es que en cada sesión Édgar desgranaba y volvía a armar cuidadosamente los más diversos conceptos de Lyotard, Deleuze, Foucault, especialmente, sin dejar de exponerlos a su propio afuera, sin dejar de escudriñarlos hasta el límite de la incoherencia en un esfuerzo por salir del lenguaje descriptivo del acontecimiento como hecho o incluso como evento, hacia el territorio experimental y cognitivo de las fuerzas, las intensidades, las multiplicidades. El resultado era, normalmente, una serie de certezas sobre los conceptos puestos en discurso y una serie extraña de sugerencias acerca del afuera que provocaban las diversas disquisiciones sobre nuevas formas de hacer y experimentar la filosofía. Eso es lo que quisiera llamar la risa categórica, o la risa transductiva. Categórica porque el asombro y la paradoja había venido a sustituir el deber ser del ejercicio filosófico como resultado de una responsabilidad a priori con el bien y la verdad. Y transductiva, porque entre el universo del concepto y el del acontecimiento, tan lejanos en el plano de la relación sujeto/objeto, ahora aparecía una lógica que no podía ser simplemente inductiva o deductiva, sino que en la definición misma del concepto como acontecimiento asomaba constantemente el recurso peirceano de la transducción, para sugerir ese plus que hacía lógicamente componibles los universos aparentemente disyuntivos del acontecimiento y el concepto.

El asunto es que la forma de reconocer esa composición posible normalmente era a través de la risa. Yo creo que la risa de Édgar, en ese sentido, sigue siendo especialmente potente y significativa. Desde luego, también era una risa perversa, en cuanto mucho de lo que pasa en el concepto respecto del acontecimiento se expresa el desajuste entre el cuerpo y la proposición, entre lo que decimos y lo que hacemos, entre el deseo y su expresión, entre la gramática apolínea del cuerpo y la semántica dionisíaca que propicia el encuentro con los otros. Pero lo más interesante era el estallido de la risa ante la aparición de la diferencia, su emoción ante el gesto o el pensamiento en plena diferenciación, fuera por efecto de una flexión expresiva o de sentido. En cualquier caso, esa risa 
terminaba por convertirse en una risa categórica que anunciaba la novedad, que señalaba el acontecimiento como diferencia. Yo sospecho que esa risa no era simplemente una salida condescendiente hacia el afuera, sino también el resultado paradójico del trabajo arduo, enorme, que significa la producción del concepto, como si la risa fuese el complemento inevitable del rigor, a veces extenuante, en medio del cual se desarrollaba cada sesión de esa suerte de oráculo pausado y vigilante en que se convertían los cursos de Édgar para sus iniciados.

\section{Referencias bibliográficas}

Garavito, E. (1997). La transcursividad. Crítica de la identidad psicológica. Medellín: Universidad Nacional.

Garavito, E. (1999). Escritos escogidos. Medellín: Universidad Nacional. 